\title{
An alternative path to the cecum: nicorandil- associated diverticular sigmoido-cecal fistula
}

Colonic fistulas are rare and, in patients without inflammatory bowel disease or neoplasia, are usually related to complicated appendicitis or diverticulitis. We report a case of sigmoido-cecal fistula with no known history of ileocolonic disease.

A 76-year-old caucasian man was referred for colonoscopy due to change in bowel habits (recurrent bouts of mild diarrhea) for the previous 6 months. The patient denied having fever, abdominal pain, gastrointestinal bleeding, prior abdominal trauma, or surgery. He had a history of hypertension and ischemic heart disease; his usual medication consisted of nicorandil, carvedilol, candesartan, acetylsalicylic acid, pravastatin, and pantoprazole. Colonoscopy revealed multiple large diverticula on the sigmoid colon and, adjacent to the appendix, a smooth round orifice wide enough to allow the colonoscope to pass (11 mm wide), leading to what appeared to be the sigmoid colon, with the distal portion of the colonoscope in view ( Video 1; $\bullet$ Fig. 1).

A barium enema confirmed a wide sigmoido-cecal fistula ( $\bullet$ Fig. 2).

Intra-abdominal fistulas are a known complication of diverticular disease, but patients usually have a long history of symptoms and previous episodes of diverticulitis [1]. Fistulization occurs mostly to the bladder (65\%) or vagina $(25 \%)$; colocolonic fistulas are rare [2]. Nicorandil, a potassium channel opener with a nitrate component, has been used for over 20 years in the management of angina. Recognized side effects of this drug include oral, gastrointestinal, and genital ulceration, as well as fistula formation in rare cases [3]. A recent case-control study by McDaid et al, involving 153 patients with diverticular disease [4], suggests that nicorandil may be associated with fistula formation in such patients, with an odds ratio of 7.8. The pathogenesis and natural history of nicorandil-induced ulceration and fistulization are still not clear.

\section{Video 1}

View from the cecal side of the fistula showing the moving colonoscope in the sigmoid colon.
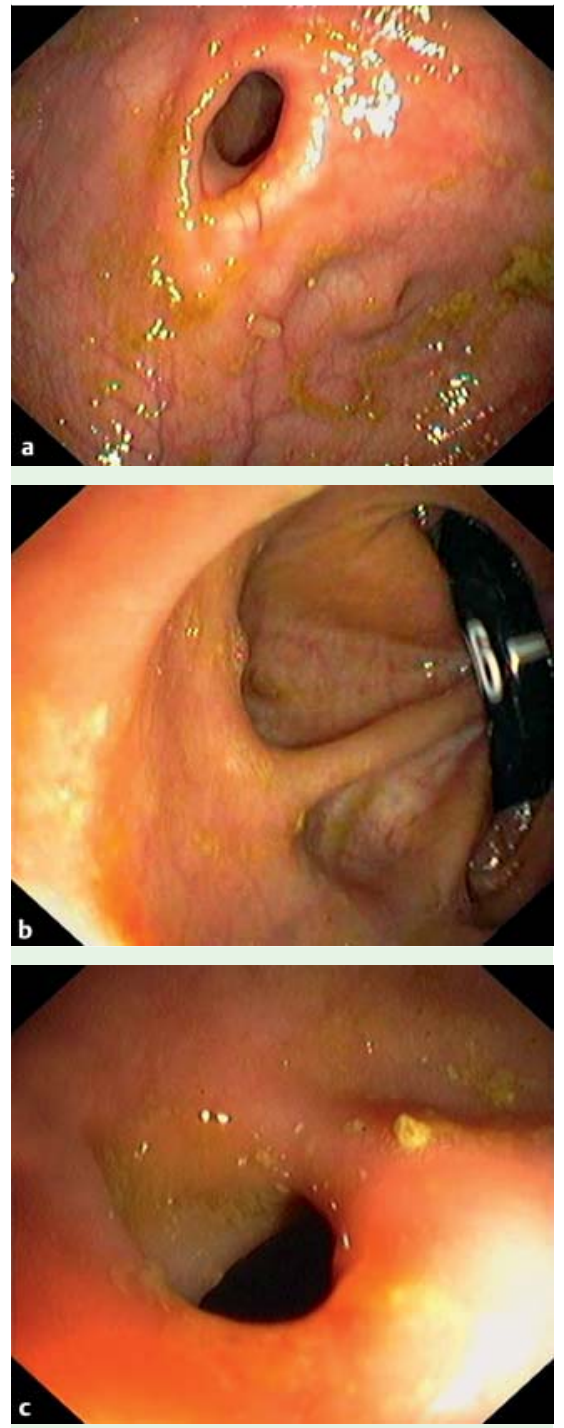

Fig. 1 Passage through the fistula from the cecum to the sigmoid.

In the present case, the authors believe that the use of nicorandil could explain the paucisymptomatic presentation and large caliber of what seemed to be a diverticular fistula.

Endoscopy_UCTN_Code_CCL_1AD_2AG

Competing interests: None

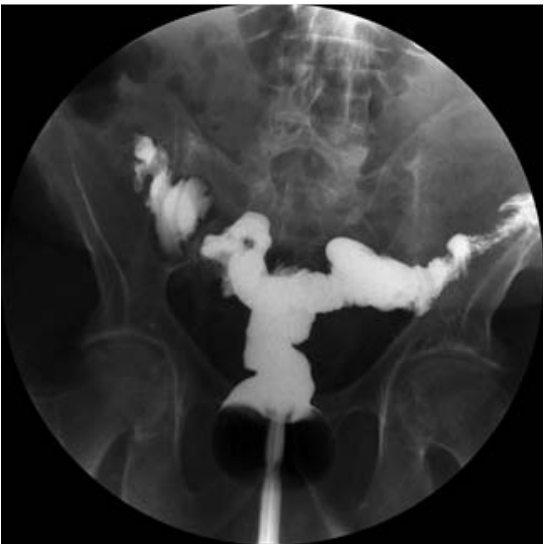

Fig. 2 Barium enema showing the large-caliber fistula between the cecum and sigmoid colon.

\section{G. Ramos, J. Coimbra, J. Barreiras,}

\section{A. D. Marques}

Gastroenterology Department, Hospital de Santo António dos Capuchos, Centro Hospitalar de Lisboa Central E.P.E., Lisbon, Portugal

\section{References}

1 Wong SK, Ho YH, Leong AP, Seow-Choen F. Clinical behavior of complicated right-sided and left-sided diverticulosis. Dis Colon Rectum 1997; 40: 344-348

2 Woods RJ, Lavery IC, Fazio VW et al. Internal fistulas in diverticular disease. Dis Colon Rectum 1988; 31: 591

3 Goh C, Wong SC, Borland C. Persistent orocutaneous and anal fistulae induced by nicorandil: a case report. J Med Case Rep 2009; 3: 119

4 McDaid J, Reichl C, Hamzah I et al. Diverticular fistulation is associated with nicorandil usage. Ann R Coll Surg Engl 2010; 92 (6): $463-465$

\section{Bibliography}

DOI $10.1055 / \mathrm{s}-0030-1256006$

Endoscopy 2011; 43: E90

(c) Georg Thieme Verlag KG Stuttgart - New York . ISSN 0013-726X

\section{Corresponding author}

\section{G. Ramos, MD}

Gastroenterology Department

Hospital de Santo António dos Capuchos

Centro Hospitalar de Lisboa Central E.P.E.

Al. Sto. António dos Capuchos

1169-050 Lisbon

Portugal

Fax: +351-213158612

goncalo.ramos@hotmail.com 